
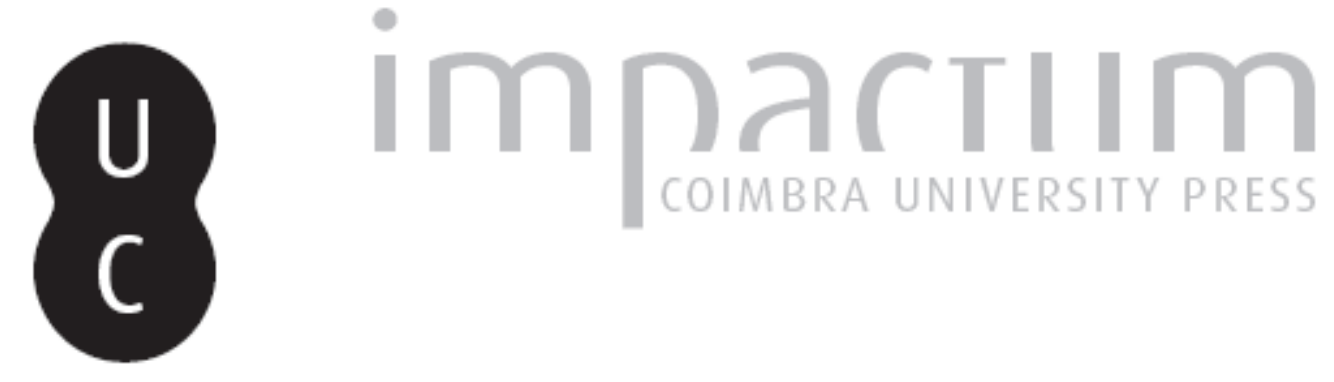

[Recensão a] Jean-Loup Abbé, À la conquête des étangs. L'aménagement de l'espace en Languedoc méditerranéen (XIle-XVe siècle)

Autor(es): $\quad$ Morujão, Maria do Rosário Barbosa

Publicado por: Centro de História da Sociedade e da Cultura

URL persistente:

URI:http://hdl.handle.net/10316.2/39712

DOI:

DOI:http://dx.doi.org/10.14195/1645-2259_6_10

Accessed : $\quad$ 26-Apr-2023 12:14:15

A navegação consulta e descarregamento dos títulos inseridos nas Bibliotecas Digitais UC Digitalis, UC Pombalina e UC Impactum, pressupõem a aceitação plena e sem reservas dos Termos e Condições de Uso destas Bibliotecas Digitais, disponíveis em https://digitalis.uc.pt/pt-pt/termos.

Conforme exposto nos referidos Termos e Condições de Uso, o descarregamento de títulos de acesso restrito requer uma licença válida de autorização devendo o utilizador aceder ao(s) documento(s) a partir de um endereço de IP da instituição detentora da supramencionada licença.

Ao utilizador é apenas permitido o descarregamento para uso pessoal, pelo que o emprego do(s) título(s) descarregado(s) para outro fim, designadamente comercial, carece de autorização do respetivo autor ou editor da obra.

Na medida em que todas as obras da UC Digitalis se encontram protegidas pelo Código do Direito de Autor e Direitos Conexos e demais legislação aplicável, toda a cópia, parcial ou total, deste documento, nos casos em que é legalmente admitida, deverá conter ou fazer-se acompanhar por este aviso.

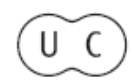




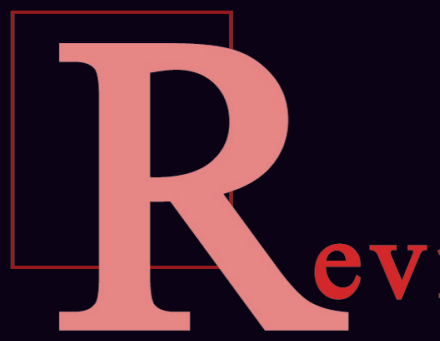

\section{da Sociedade e da Cultura}

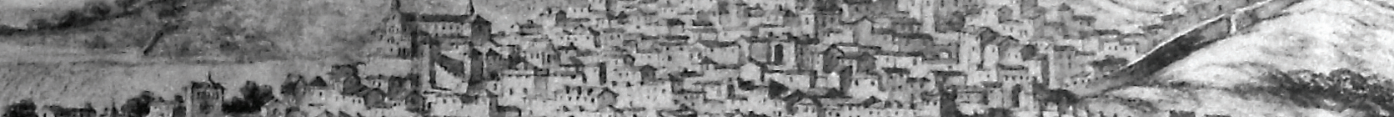

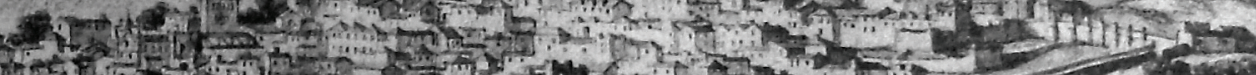

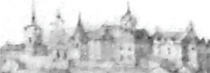

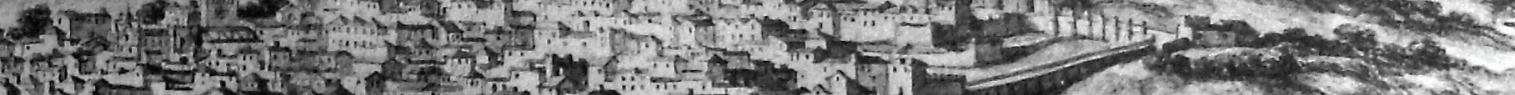

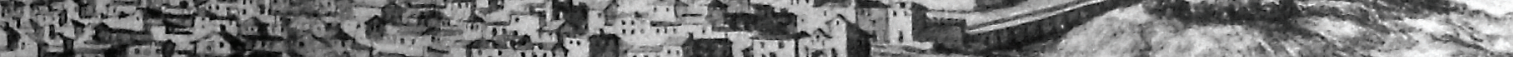

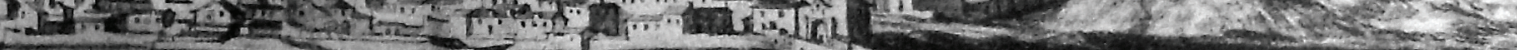

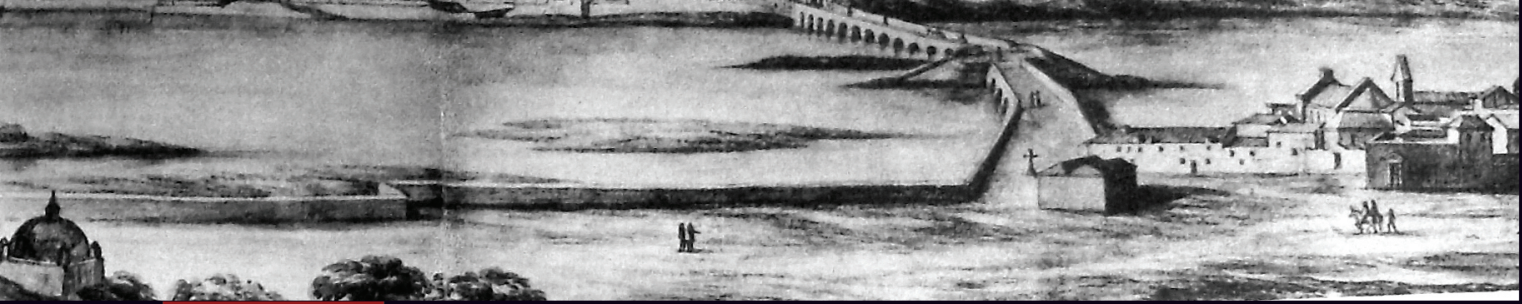

Centro de História da Sociedade e da Cultura Universidade de Coimbra

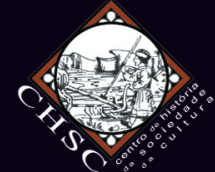




\section{Recensão crítica}

Jean-Loup Abbé, À la conquête des étangs. L'aménagement de l'espace en Languedoc méditerranéen (XII ${ }^{e}-X V^{e}$ siècle), Toulouse, Presses Universitaires du Mirail, col. “Tempus”, 2006, 331 p. ISBN: 2-85816-829-6

Este livro de Jean-Loup Abbé, que constitui a sua "mémoire d'habilitation à diriger les recherches" apresentada à Universidade de Toulouse-Le Mirail, aborda a temática do comportamento da sociedade medieval na organização e no ordenamento dos espaços húmidos, estudando as relações que os homens do Languedoc mediterrânico estabeleceram com os "étangs" característicos dessa região de França, no período que medeia entre os séculos XII e XV.

O livro divide-se em 6 capítulos, antecedidos por uma introdução e seguidos por uma conclusão, a que o Autor acrescentou, além da indicação das fontes e da bibliografia utilizadas, a transcrição de cinco documentos designados como "pièces justificatives"; anexos contendo mapas antigos e modernos, tabelas e fotografias; e um valioso léxico do principal vocabulário sobre a temática usado nos documentos do Languedoc. No final, surgem os índices: geográfico, onomástico e de matérias.

O capítulo 1 é dedicado a uma síntese sobre o ordenamento das zonas húmidas desde a Antiguidade à Idade Média, à escala europeia, contextualizando assim a investigação efectuada e demonstrando como o comportamento humano face a essas zonas variou conjunturalmente, condicionado por factores económicos, sociais e decerto também naturais, tanto climáticos como hidrológicos.

\footnotetext{
${ }^{1}$ Este termo corresponde em português tanto a charcos como a lagoas, o que me leva a preferir não o traduzir.
} 
No capítulo 2, o Autor define o "corpus" a investigar e as fontes para o seu estudo. Não procurando a exaustividade, seleccionou os "étangs" sobre os quais existia um maior número de informações e a documentação era mais rica, num total de 54, dos quais doze são os principais. As fontes analisadas não são apenas medievais, mas também modernas, e, além dos documentos propriamente ditos (provenientes, na sua maioria, de fundos eclesiásticos), incluem mapas e cadastros de propriedades da Época Moderna. Quanto a estudos sobre a matéria que podiam auxiliar a investigação, numerosos trabalhos recentes no âmbito da investigação paleoambiental, sobretudo de geoarqueologia, renovaram totalmente o conhecimento que se tinha acerca das zonas húmidas, fornecendo portanto dados da maior importância para a investigação realizada.

O capítulo 3 trata da caracterização dos "étangs" na Idade Média e do seu significado e importância para os homens que junto deles viviam, partindo das informações conservadas tanto nos "arquivos do solo", segundo a expressiva designação do Autor, como nos documentos escritos. Estas fontes revelam que as zonas húmidas do Languedoc conheceram diferentes momentos durante o período medieval, com alterações climáticas e hidrológicas que fizeram variar o nível das águas ao longo dos séculos: mais alto antes do século XII, mais baixo a partir de então e até aos finais do século XIII, altura em que começou uma nova fase húmida que fez aumentar de novo a quantidade de água dos "étangs". A relação do homem com estes espaços variou também no decurso destes séculos, em conexão com as referidas mudanças do nível das águas. Até ao século XII, o homem explorava os recursos próprios destas zonas húmidas. De meados de Undecentos até ao século XIV, foi a época das secagens, favorecidas pela diminuição das águas dos "étangs", transformados então em terras férteis destinadas ao cultivo de cereais ou, em alguns casos, em pastagens, modificando-se assim profundamente a paisagem do Languedoc.

O capítulo 4 estuda a cronologia das secagens, a forma como eram planeadas e os agentes que nelas intervinham. A iniciativa de secar os espaços húmidos, ao contrário do que sucedera no passado, não partiu do poder central (enfraquecido neste período de pleno feudalismo), mas sim dos senhores da região proprietários das zonas húmidas. São eles quem decide proceder à secagem, assim como determinam os modos de a executar. No século XII, 
foi levada a cabo sobretudo por templários e cistercienses, que colocavam as novas terras sob o seu senhorio directo. Na centúria seguinte, são essencialmente os senhores laicos que aderem a esta dinâmica, entregando os terrenos conquistados às águas a foreiros ou a intermediários, que se encarregavam dos encargos do processo de secagem e as davam a explorar a terceiros. A partir de 1300, as secagens tornam-se projectos que envolvem a associação de diversos senhores, proprietários em simultâneo dos "étangs". Os intermediários que recebiam as terras eram burgueses ricos das cidades e vilas próximas; o seu investimento na exploração agrícola destes novos e férteis terrenos prova a ligação cada vez mais estreita entre o mundo urbano e o mundo rural que se fazia sentir nos finais da Idade Média.

Para se poder iniciar o processo de secagem era ainda necessário obter autorização dos senhores das terras que seriam atravessadas pelos fossos e galerias de escoamento. Em geral, o consentimento era dado mediante o pagamento de um direito de entrada e de um censo, e as obras podiam ser iniciadas. A sua realização constitui o tema do capítulo 5. Quem as executava, a formação da mão-de-obra, as técnicas seguidas são questões que permanecem em grande medida por responder. Os dados apontam para que o pessoal competente fosse contratado no seio do mundo urbano que investia na exploração destes terrenos. As obras exigiam conhecimentos técnicos de que fazem eco algumas referências documentais e, sobretudo, tratados sobre agrimensura e delimitação de terrenos, como os de Bertrand Boysset, agrimensor que viveu entre meados do século XIV e cerca de 1416, que fornecem dados de enorme importância para a história das técnicas.

Das obras realizadas resultavam terras novas que deviam ser organizadas, divididas em parcelas e cultivadas. O capítulo 6 estuda, precisamente, esta matéria e o lugar que os "étangs" secos vieram ocupar na estruturação do espaço medieval. Um lugar especial, dado que o seu ordenamento parcelar era determinado pelo traçado dos fossos de drenagem e das galerias dos aquedutos. A especificidade da paisagem assim criada permaneceu, aliás, ao longo dos séculos, levando a que, ainda hoje, a maioria dos "étangs" secos na Idade Média seja identificável.

Estes, de forma muito sintética, são os temas abordados por Jean-Loup Abbé, numa obra que constitui, sem dúvida, um importante contributo para a história das relações entre o homem medieval e o espaço, assim como um 
bom modelo metodológico para estudos a realizar sobre uma temática ainda muito pouco explorada em Portugal.

Maria do Rosário Barbosa Morujão 